\title{
Noções de fronteira na teoria e práxis do regionalismo \\ Uma visão crítica
}

Notions of border in regionalism theory and praxis

A critical overview

\section{Nociones de frontera en la teoría y praxis del regionalismo Una visión crítica}

Gustavo Matiuzzi de Souza*

\begin{abstract}
Resumo: Este artigo fornece um panorama conciso das noções de fronteira na teoria e nas práxis do regionalismo. Também se discute o aumento, na última década, das barreiras fronteiriças neste mundo globalizado e a sua relação com o regionalismo. Através de uma aproximação histórica à construção de teorias, considera-se as ideias implícitas de fronteira derivadas dos desenvolvimentos teóricos e empíricos do regionalismo. Este paper conclui que o antigo regionalismo indica uma noção de fronteira como separação. O novo regionalismo implica em uma noção de fronteira como filtro. A atual onda do regionalismo comparado identifica dois processos aparentemente contraditórios (regionalismo multinível e nacionalismo) que acionam a formação de regiões (trans)fronteiriças incorporadas em teias entrelaçadas de redes globais, exigindo uma perspectiva globalista no estudo dessas dinâmicas.
\end{abstract}

Palavras-chave: Fronteira. Regionalismo. Regionalismo comparado. Integração. Globalização.

Abstract: This article provides a concise and critical overview of the notions of border within regionalism theory and praxis. It also discusses the last decade's increase of border barriers in this globalized world and its relation to regionalism. We provide a historical approach to theoretical construction and consider implied ideas of border derived from theoretical and empirical developments of regionalism. This paper finds that old regionalism indicates a notion of border as separation; new regionalism implies a notion of border as filter. The current wave of comparative regionalism identifies two apparently contradictory processes (multilevel regionalisms and nationalisms) that actuate the formation of (cross) border regions embedded into tangled webs of global networks, which requires a globalist perspective of regionalist dynamics.

Keywords: Border. Regionalism. Comparative regionalism. Integration. Globalization.

Resumen: El objetivo de este artículo es proporcionar una visión general concisa y crítica de las nociones de frontera dentro de la teoría y praxis del regionalismo. También tiene como objetivo analizar el aumento de las barreras fronterizas en la última década

\footnotetext{
* Université de Liège (Liège, Belgium).

autor.dados_biográficos
}

Civitas, Porto Alegre, v. 18 , n. 2, p. 245-261, maio-ago. 2018 
en este mundo globalizado y su relación con el regionalismo. Brindamos un enfoque histórico a la construcción teórica y consideramos ideas implícitas de frontera derivadas de desarrollos teóricos y empíricos del regionalismo. Este documento encuentra que el viejo regionalismo indica una noción de frontera como separación; el nuevo regionalismo implica una noción de frontera como filtro. La ola actual del regionalismo comparado identifica dos procesos aparentemente contradictorios (regionalismos multinivel y nacionalismos) que impulsan la formación de regiones (trans)fronterizas incrustadas en cadenas enmarañadas de redes globales, lo que requiere una perspectiva globalista de la dinámica regionalista.

Palabras clave: Frontera. Regionalismo. Regionalismo comparado. Integración. Globalización.

\section{Introdução}

Duas perguntas guiam este breve panorama sobre o regionalismo (internacional), as quais intentam estender o pensamento da relação teórica e empírica entre os processos regionais e a fronteira: (1) Como o regionalismo compreendeu as fronteiras e seu papel nas dinâmicas regionalistas na história? (2) Como o regionalismo comparado reconhece as fronteiras face à política que hoje recrudesce as barreiras (inter)nacionais? O objetivo deste artigo é fornecer um contorno conciso das noções de fronteira dentro da teoria do regionalismo e de suas práxis. Também visa discutir o aumento, na última década, das barreiras fronteiriças neste mundo globalizado e sua relação com o regionalismo. Importante salientar o objetivo não contemplado de prestar contas exaustivas da produção teórica, da mesma forma que não está prevista a análise dos conceitos de fronteira. Antes, este paper apenas reflete sobre as noções intrínsecas de fronteira dentro de grandes processos e teorias regionalistas de 1945 aos dias atuais.

Regionalismo(s) e fronteiras(s) são construtos sociais entrelaçados. Como ideias sociais, eles afetam um ao outro tanto em termos funcionais quanto conceituais; como instituições sociais, são partes integrantes das mesmas redes multiescalares. No entanto, a produção de análises teóricas sobre esta relação permanece incipiente. Como afirmado por Vaughan-Williams (2009), as fronteiras ainda são um ponto cego na teoria das Relações Internacionais, e ainda mais nas teorias do regionalismo. Este artigo pretende preencher esta lacuna conectando as ondas (ou fases) constituídas (teóricas e empíricas) do regionalismo com o desenvolvimento paralelo das noções de fronteira e seus papéis.

A primeira parte deste artigo apresenta as bases teóricas e conceituais deste panorama, no qual propomos uma compreensão do regionalismo e da 
fronteira e desenvolvemos um quadro analítico. A segunda e terceira partes estão focadas na análise das duas primeiras ondas de regionalismo vis-à-vis os múltiplos papéis da fronteira no desenvolvimento histórico de ambas as ideias/ instituições. A quarta seção elabora a atual fase do regionalismo, discutindo a elevação, na última década, das barreiras fronteiriças. Observações finais concluem o artigo.

\section{Inter-relacionando o regionalismo e as noções de fronteira}

O regionalismo é qualquer processo (social, cultural, econômico ou político) que ocorra dentro, para ou através de uma região. É um espaço em que os players (públicos ou privados, estatais ou não-estatais) atuam e produzem normas (Santander, 2012). O regionalismo também pode ser considerado um tipo de ordem (como configurações de poder, por exemplo) e, nesta perspectiva, está intimamente ligado à formação de identidades coletivas e à criação de fronteiras e limites (ver Lapid, 2001). ${ }^{1}$ Isso revela a faceta relacional do regionalismo e das fronteiras, bem como do esforço conceitual aqui realizado. A dinâmica regionalista desempenha um papel expressivo ao dar às fronteiras um significado político - e, portanto, prático - na medida em que tais relações se desenrolam. Quanto à sua influência sobre o papel da fronteira, o regionalismo funciona em uma dicotomia não exclusiva, ultrapassando as delimitações políticas delineadas pelas fronteiras internacionais enquanto preserva os limites e as lógicas territoriais (cf. Smouts e Badie, 2006 [1996]). O regionalismo pode funcionar como um mecanismo de fuga - como processos políticos destinados a evitar a territorialidade do estado - ou como uma ferramenta de reforço para o seu papel limitante. Ambas as funções coexistem em um espaço dinâmico de inter-relações políticas contínuas.

Saber que função de fronteira está sendo utilizada, por que e para quem depende dos contextos históricos em que os atores-chave do regionalismo (seja o estado, os setores industrial/comercial, a sociedade civil etc.) são colocados, bem como dos esforços teóricos para abranger tal realidade contextual. Isso indica que teoria e práxis estão inter-relacionadas. A compreensão dos contextos (geo)políticos em que, e através do qual, os pensadores de relações internacionais formularam seus conceitos e noções é fundamental no processo de captação de modelos teóricos e quadros conceituais desenvolvidos. Olhar as

\footnotetext{
${ }^{1}$ Esta tríade é o foco do Projeto IBO ("Identities, Borders, Orders"), também conhecido como Grupo de Las Cruces, que está engajado em um esforço interdisciplinar para compreender as inter-relações complexas entre esses conceitos-chave da teoria das Relações Internacionais. Veja Albert, Jacobson e Lapid (2001) para mais detalhes.
} 
teorias à luz dos contextos históricos facilita a compreensão não somente da construção do conhecimento a respeito do regionalismo e da fronteira, mas particularmente da maneira pela qual os estudiosos compreenderam estes objetos.

Após a consolidação do estado-nação, principalmente após o final da Segunda Guerra Mundial, três fases do regionalismo apresentaram distintos eventos socioeconômicos e políticos e explicações teóricas que moldaram a compreensão dos papéis tanto do regionalismo quanto da fronteira. As fases do antigo regionalismo (1945-1990), novo regionalismo (1990-2000), e regionalismo comparado (2000-hoje) são macrocenários contrastantes. Ordens mundiais diversas, várias formas de organizações internacionais e interesses cambiantes (Söderbaum, 2016) moldaram os papéis do regionalismo e os papéis da fronteira no âmbito das relações regionais e dos sistemas internacionais. Assim, as narrativas teóricas sobre os desenvolvimentos regionais seguem o contexto histórico de cada fase, fornecida a contextualização necessária.

Há diferenças significativas em relação à investigação regionalista e às noções de fronteira dentro de cada período. $\mathrm{O}$ antigo regionalismo foi caracterizado pelo predomínio da epistemologia racionalista, uma vez que se refere ao período de consolidação das teorias das relações internacionais (realista e racionalista no seu nascimento). A fronteira foi compreendida sob os seus atributos de separação. O novo regionalismo testemunhou o surgimento da epistemologia refletivista, que tendia a conceber a fronteira sob suas propriedades enquanto "filtro". O regionalismo comparado é plural (ou eclético) em seu núcleo, capaz de navegar através de epistemologia racionalista-refletivista. Ele permite vários entendimentos de fronteira e é o mais adequado para apreender as mudanças aceleradas no cenário global ao qual o regionalismo é integrado. No entanto, as tensões levantadas em relação às políticas fronteiriças hoje em dia têm exigido uma visão mais global sobre a forma como o regionalismo comparado compreende tanto as regiões quanto as fronteiras.

\section{Antigo regionalismo: fronteiras como separação e controle}

$\mathrm{O}$ antigo regionalismo abrange a chamada teoria clássica da integração regional (1945-1970) e suas revisões posteriores (1970-1990) que concentraram seus enfoques na experiência europeia do regionalismo, estendendo-os a uma certa comparação com outras experiências ao redor do globo, com especial atenção à América Latina e ao Sudeste Asiático. A principal questão por trás dessas teorias focou-se em saber como os estados 
poderiam manter a paz e reconstruir as economias após o final da Segunda Guerra Mundial. Eles acompanharam os desenvolvimentos históricos das cinco décadas seguintes, tentando fornecer explicações para a criação de entidades integradas supranacionais na Europa (em todos os seus altos e baixos); para as configurações altamente cooperativas que levaram à assinatura de dezenas de acordos regionais na América Latina (e o desaparecimento da maioria deles); e para os sistemas de cooperação informais construídos na Ásia.

A Guerra Fria, alimentada pela crescente tensão entre o Oriente e o Ocidente, o poder hegemônico exercido pelos Estados Unidos (EUA) e pela União Soviética, na Europa, América Latina, Ásia e no resto do mundo, patrocinou em grande parte o recrudescimento das fronteiras e a proteção dos estados-nação. Entre as diversas rotas tomadas pelos países europeus para lidar com o desastre socioeconômico pós-guerra em um ambiente político sensível, a reconstrução das fronteiras e a delimitação do espaço e do território encontraram lugar cativo em todas as agendas nacionais (Newman, 2006). No entanto, conscientes dos perigos do nacionalismo, os decisores políticos e acadêmicos projetaram tratados e engendraram acordos para superar a rigidez territorial do estado-nação. Alter e Steinberg (2007) mostram, por exemplo, que o papel principal da Comunidade Europeia do Carvão e do Aço (Ceca), criada em 1951, era assegurar aos países europeus que a Alemanha não voltaria a desenvolver uma propensão perigosa e proeminente de poder e reconstruir a parceria franco-alemã, com impacto minoritário na economia regional. A Ceca também se tornou um modelo para acordos subsequentes e um fórum relevante para discussões políticas. Em suma, os objetivos dessa organização e de acordos posteriores foram definidos em termos de segurança através do comércio.

Por outro lado, a fundação da Associação Latino-Americana do Livre Comércio (Alalc), nove anos após a Ceca, demonstrou ser fundamentada em objetivos diferentes. A Alalc destinou-se a criar uma área de comércio livre para usufruir dos benefícios de uma economia integrada, aumentando os mercados nacionais e aprofundando os laços comerciais intrarregionais através da progressiva liberalização das tarifas e taxas - promovendo, assim, as condições para um mercado comum (Díaz, 2015). Embora a Alalc não tenha alcançado seus objetivos, o que importa aqui é que (diferentemente da Europa) o regionalismo foi um meio para resolver questões macroeconômicas nos países da América Latina e alcançar o desenvolvimento. O regionalismo também visou garantir a construção das nações empreendendo tal estratégia (cf. Söderbaum, 2016). Da mesma forma, a fundação da Associação de Nações do Sudeste Asiático (Ansea), em 1967, foi impulsionada pela necessidade de 
fomentar o desenvolvimento econômico e reduzir o conflito regional, sem interferir nos assuntos internos. De muitas maneiras bem-sucedida, a Ansea logrou criar um ambiente regional mais estável - política e economicamente particularmente nas suas duas primeiras décadas de existência (Yue, 1996). Em comum, as três anedotas demonstram que, apesar de reconhecer a necessidade de uma cooperação que ultrapassasse as fronteiras estatais, os projetos regionais durante esta onda/fase as mantiveram em seus níveis mais altos. Os europeus, ignorando as funções de separação das fronteiras para gerar um ambiente político mais calmo; os latino-americanos, tentando integrar, mas recusandose a reduzir os obstáculos comerciais e defendendo a produção nacional; os asiáticos, promovendo segurança regional através da proteção do território.

As noções de fronteira na antiga teoria do regionalismo seguiram, então, tais desenvolvimentos políticos regionais, que, em geral, promoveram o fortalecimento do estado-nação após a Segunda Guerra Mundial, a proteção da nation-building latino-americana em face do ambiente econômico internacional, e as políticas de segurança protecionistas do Sudeste Asiático. As teorias do federalismo, (neo)realismo, transacionalismo, (neo)funcionalismo, intergovernamentalismo e institucionalismo criaram explicações sobre como construir paz e prosperidade com integração política e/ou econômica na Europa (veja Rosamond, 2000; Wiener e Diez, 2009), também se esforçando para compreender as tentativas de integração regional na América Latina (Haas e Schmitter, 1964; Aitken e Lowry, 1972) e os sistemas cooperativos asiáticos (Leifer, 1978; Arndt e Garnaut, 1979).

Contudo, essas teorias não estavam preocupadas com as fronteiras, tampouco estavam inclinadas a teorizar os efeitos do regionalismo nas funções fronteiriças. Testemunhando a fundação de uma miríade de instituições regionais, tais teorias foram primeira e principalmente focalizadas em explicar o regionalismo conduzido pelo estado, o que os fez analisar tais organizações, seus desenvolvimentos e suas capacidades e limitações como frameworks regionais. Em relação às semelhanças ontológicas e epistemológicas, tais teorias privilegiaram o paradigma racional, formal e de cima para baixo (topdown), e a centralidade analítica do estado e de suas instituições (como o poder material, a soberania e mecanismos de controle territorial). Os atores não-estatais foram reconhecidos ocasionalmente como partes de unidades nacionais ou como geradores de demanda. Quanto às suas diferenças, as teorias do antigo regionalismo apresentaram ênfases distintas (economia, alianças políticas, comércio etc.) concentrando-se em certos aspectos da integração, tais como negociações políticas, construção institucional, poder e outros. 
Os papéis da fronteira, do ponto de vista das instituições regionais da Europa, da América Latina, da Ásia ou de outras partes foram apenas reconhecidos em relação às necessidades dos estados-nação, que estavam cientes do imperativo de reforçar as posições de segurança, comércio e desenvolvimento econômico, e aplicaram o regionalismo para conceder a suas fronteiras status provisórios dessemelhantes. Para as partes das mesmas instituições cooperativas/integrativas, as fronteiras acabariam por se tornar menos separatistas (em alguns setores); para as partes fora dos órgãos regionais, as fronteiras continuariam a ser inteiramente reforçadas. Assim, o regionalismo e a fronteira foram elementos complementares de políticas estatais relativas a (e dentro de) um sistema político global. Tal ideia anda de mãos dadas com uma definição de "integração regional” de Malamud (2011, p. 219):

[a integração regional] pode ser entendida como uma tentativa de reconstruir as fronteiras nacionais erodidas a um nível mais elevado. Portanto, pode ser interpretada como uma manobra protecionista dos estados que não podem garantir seus interesses e objetivos por si mesmos, e procuram fazê-lo em conjunto com os outros. ${ }^{2}$

No antigo regionalismo, não houve nenhuma problematização de "região" como conceito relevante, na medida em que a organização regional foi compreendida como sendo sua própria materialização. Uma noção espacial de região era, assim, inexistente. Seguindo a mesma linha de pensamento, a contiguidade territorial era um pré-requisito para a construção de regiões, isto é, a adjascência de territórios nacionais era a única maneira de formá-las. Assim, tanto em teoria como em práxis, as fronteiras externas regionais foram pensadas para trabalhar como barreiras herméticas para proteger o espaço regional de uma maneira que os estados haviam sido encontrados incapazes de fazê-lo. A continuação das funções de separação e controle das fronteiras internas regionais não dificultou, contudo, a sua relativização de acordo com as necessidades regionais específicas, embora o reforço simultâneo dessas funções de fechamento na (re)construção dos estados-nação em todo o mundo continuasse em ritmo acelerado.

\section{Novo regionalismo: fronteiras como filtros}

A fase do novo regionalismo (1990-2000) refere-se principalmente às vicissitudes da ordem mundial causadas pela globalização. Os avanços tecnológicos em comunicação e transporte mudaram a forma como os

\footnotetext{
${ }^{2}$ Tradução livre do original em espanhol.
} 
países, empresas e pessoas se relacionavam. Se na fase anterior o estadonação foi $o$ canal para e o centro de processos societais globais (internacional em seu núcleo), no novo regionalismo, tais intercâmbios eram cada vez mais transnacionais, transcendendo os territórios nacionais de maneiras não antes experimentadas, cada vez mais escapando do controle estatal. A transnacionalidade das forças motrizes das dinâmicas políticas, econômicas e culturais devido ao aumento do comércio global e dos fluxos econômicos transnacionais, a intensificação da velocidade e densidade das redes de comunicação, e a agitação aumentada entre e dentro das coletividades culturais diversas aumentaram a conscientização de uma interconexão global, o que gerou a percepção de novas oportunidades e desafios em todos os níveis da sociedade (Eriksen, 2007). O fim da Guerra Fria e o declínio da bipolaridade também alteraram a estrutura do sistema internacional.

Face a tais mudanças profundas, o regionalismo não permaneceu inalterado; tornou-se uma alternativa de políticas de nível intermediário - nem global nem nacional (Söderbaum, 2003). Seus atributos multidimensionais, não limitados a questões de economia, comércio e segurança, evidenciaram uma variedade de quadros institucionais, e uma participação mais ativa da sociedade civil e de atores corporativos (Mansfield e Milner, 1997). Dezenas de organizações foram criadas, e centenas de acordos e processos regionais foram lançados por diferentes atores com objetivos sociais, políticos e econômicos diversos. Atores não-estatais exigiram inclusão na dinâmica regionalista. Tal movimento, chamado por muitos de "regionalização" (ou regionalismo informal), tornou-se uma importante força motriz dos processos regionais. $\mathrm{O}$ estado intentou proteger sua soberania territorial face aos fluxos crescentes, transferindo o poder "para cima, para baixo e para o lado" (Perkmann e Sum, 2002, p. 4), territorializando a política. Surgiram unidades subnacionais e transnacionais de governança. Uma vez ignoradas ou negligenciadas como dispositivo secundário do sistema interestatal (Williams, 2003), as fronteiras se tornaram um trunfo para expandir os mercados e adquirir um papel relevante em uma economia cada vez mais global. ${ }^{3}$ As áreas fronteiriças foram rapidamente transformadas em polos estratégicos, numa corrida público-privada para atrair capital transnacional. A permeabilidade das fronteiras, destacada na

\footnotetext{
${ }^{3}$ Ao identificar as principais diferenças entre o antigo e o novo regionalismo, em particular a centralidade dos estados soberanos e as instituições multilaterais no primeiro e a complexidade das lógicas concorrentes e interativas no último, Hurrell (2007) também destaca a instabilidade de tais processos, que na atual fase do regionalismo comparado (ver próxima seção) tem experimentado o aumento de movimentos contraditórios e concomitantes de cooperação e desintegração, colocando as fronteiras estatais no cerne da questão.
} 
mobilidade do capital, da indústria, da informação e das pessoas, fez com que os estudiosos e os decisores políticos questionassem a sua relevância em termos econômicos dentro desta nova ordem mundial (ver Ohmae, 1995).

A heterogeneidade das novas teorias do regionalismo foi representada pela dificuldade em encontrar um terreno comum na definição e na problematização do "novo regionalismo" como conceito fundamental. Em comum, apenas uma vaga ideia de que uma fase diferente tinha começado e a tentativa de compreendê-la (cf. Dabène, 2009). A proliferação de teorias e abordagens oscilou entre variedades de teorias mainstream (ou seja, racionalistas) (perspectivas neoliberais do institucionalismo e comércio, narrativas neorrealistas), abordagens de governança multinível, construtivistas, refletivistas e perspectivas críticas, bem como as chamadas abordagens do novo regionalismo. O surgimento das narrativas construtivistas teve um impacto significativo no desafiar das convenções baseadas no racionalismo, enquanto que as abordagens refletivistas lançaram luz sobre a pergunta "para quem", assim como sobre o problema do propósito inconspícuo das dinâmicas regionalistas (Söderbaum, 2016).

Essa produção teórica proficiente foi a chave para uma análise mais detalhada sobre a fronteira. Embora ainda não ligando diretamente regionalismo e fronteira, as novas teorias do regionalismo tornaram-se conscientes dos efeitos da globalização em macro e microníveis (de realidade social e de níveis de análise), bem como das conexões empíricas que as macrorregiões e microrregiões compartilhavam. Söderbaum (2005) realçou a necessidade de transcender o estado-nação como categoria espacial central, movendo-se em direção a uma perspectiva mais multiescalar. $\mathrm{O}$ espaço regional e as escalas do regionalismo estavam, então, no núcleo de tal discussão. Com esses níveis já reconhecidos como elementos analíticos relevantes, De Lombaerde (2010) desenvolveu uma proposta para vincular as comunidades acadêmicas que tendem a se concentrar em macro ou microrregiões, sugerindo assim novos caminhos de pesquisa e uma compreensão mais clara das relações globais. As análises da abordagem da ordem mundial, inspiradas no pensamento coxiano, de Gamble e Payne (1996), Hook e Kearns (1999), e Breslin e Hook (2002) reconheceram a existência de regiões de centro e periferia, problematizando microrregiões, bem como suas linhas fronteiriças. As fronteiras estavam sendo usadas para assegurar a inclusão de certas microrregiões no sistema econômico global, tornando-se o foco de uma reestruturação produtiva no mundo. $\mathrm{O}$ que essas teorias identificaram foi o caráter filtrante das fronteiras - abertas ao capital, aos produtos e à informação; fechadas para indivíduos de regiões periféricas. Não só entendidas como um ponto de choque e um 
limite, mas como uma área de transição entre a dinâmica subnacional (Leloup e Stoffel, 2001), a inserção global das fronteiras acentuou sua função como uma estrutura multidimensional de articulação.

A relação entre o novo regionalismo e as fronteiras, na teoria e na prática, é de oposição parcial. Por um lado, o ímpeto dos fluxos globais/globalizantes correu contra a continuidade das fronteiras, de forma que numerosos estudiosos previram sua extinção. Por outro lado, as fronteiras foram fatoreschave na exploração do posicionamento relativo de determinados territórios no âmbito do sistema transnacional em expansão. O principal progresso desta onda pode ser identificado como o reconhecimento das fronteiras e das regiões fronteiriças como categorias relevantes para a teoria do regionalismo, bem como para o avanço empírico da dinâmica regionalista. A persistência em relegar a fronteira como conceito significativo para outras comunidades acadêmicas (por exemplo, geógrafos políticos, sociólogos e antropólogos) por parte dos estudiosos do regionalismo, no entanto, posicionou-a - ainda - em posição inferior na teoria do novo regionalismo, ofuscando suas capacidades de explicar as alterações das políticas e sistemas fronteiriços nos ambientes regionais.

\section{Regionalismo comparado: fronteiras como componentes de sistemas multicamadas}

A globalização tornou-se inevitável, bem como o advento de inúmeros atores e fenômenos de escala global. $\mathrm{O}$ terrorismo e a não-tradicional guerra sobre o terror; as potências emergentes e a formação de novos polos políticoeconômicos; o aumento das intervenções em conflitos de terceiros e a "responsabilidade de proteger" (R2P); a intensificação de conflitos em estados frágeis e as consequências negativas na economia global e na estabilidade nacional; recorrentes crises econômicas e danos financeiros; aumento da desigualdade social e econômica. A lista não termina. Esta nova ordem mundial é progressivamente mais frágil e volátil, assim como o são o estado e os mecanismos convencionais utilizados para responder às demandas internas e externas (cf. Sørensen, 2016). A fase atual do regionalismo comparado (2000-hoje) envolve a necessidade de lidar com essas questões, que requerem uma governança multicamada, e que envolvem a agência de vários atores no cenário global (De Lombaerde e Söderbaum, 2013).

Muitos autores (Fawn, 2009; Burki, 2011; Strange, 2014; Söderbaum, 2016; Vivares, 2018) concordam que, em face desses intricados assuntos, atores estatais e não-estatais optaram por utilizar o regionalismo como um meio preponderante para assegurar a sua própria existência e/ou tirar proveito das 
novas possibilidades que os sistemas globais proporcionam. A centralidade das regiões em oferecer soluções para as contradições das relações globais deste século - (inter)nacionalismo e globalismo, estados e mercados, segurança e insegurança - é o cerne da teoria do regionalismo comparado (Katzenstein, 2005). A integração progressiva entre os membros da União Europeia (UE) e o seu alargamento em direção ao leste no início dos anos 2000 (Moravcsik e Vachudova, 2003), a busca latino-americana pela autonomia regional (em uma ordem mundial pós-hegemônica) e o fortalecimento das instituições da América do Sul para lidar com assuntos de política regional (Riggirozzi e Tussie, 2012), e a criação de múltiplas formas de inter-regionalismo (Baert et al., 2014; Mattheis e Litsegård, 2017) pareciam corroborar o fortalecimento da significância do regionalismo nos assuntos mundiais.

No que diz respeito aos fundamentos teóricos, as abordagens extraídas de narrativas de inspiração sociológica, agora muito mais desenvolvidas como formas alternativas para explicar o regionalismo (como o refletivismo e as teorias críticas) têm proporcionado uma visão abrangente e mais complexa sobre "os porquês e os comos" da formação das regiões (Acharya, 2012), abrindo caminhos rumo a metodologias e teorias plurais (ou ecléticas) (Söderbaum, 2016) - embora ainda não seja claro como aplicar uma epistemologia eclética. Fato é que as teorias mainstream das ondas anteriores agora compartilham espaço com novos entendimentos da dinâmica regionalista, projetados para lidar com as rápidas mudanças nas relações globais, cujas visões tradicionais não conseguiram explicá-las. As múltiplas formas de região estabelecidas nesta onda permitiram a comparação entre organizações, regiões informais, sub-regiões, regiões subnacionais, estados etc. em termos econômicos, sociais, culturais, políticos e simbólicos (cf. Van Langenhove, 2012).

As fronteiras, agora estudadas de forma mais diversificada, têm lentamente feito a sua rota nas teorias do regionalismo comparado. Elas começaram a ser analisadas como microprocessos, como dinâmicas informais (de regionalização), ou simplesmente como processos sociais relevantes do regionalismo. Talvez o principal avanço tenha sido identificar a fronteira em suas capacidades de construção regional (region-building) dentro de um ambiente de governança multinível. Entre numerosos conceitos criados, "borderland" reflete tais tentativas de entender as fronteiras dentro dos sistemas regionais (veja Matiuzzi de Souza, 2017). No entanto, as fronteiras persistem como fator a ser explorado em estudos comparativos do regionalismo, particularmente nas macroanálises. Permanece a falta de uma investigação que vincule as fronteiras à política regional e a outras dinâmicas regionais de forma comparada (não isolada), com poucas exceções feitas no estudo da mobilidade 
através de organizações regionais (ver Arcarazo e Geddes, 2014; Gülzau et al., 2016).

As ocorrências globais da última década intrincaram ainda mais o (já complexo) sistema global interconectado em que as regiões são (trans) formadas. Dentre elas, (1) as crises econômicas e financeiras que impactaram o mundo na última década (a catástrofe bancária americana (2007), a crise da dívida europeia (2008), a recessão econômica global (2009)) e a subsequente instabilidade política mundial de ambas políticas domésticas e relações internacionais que se espalharam pelos continentes; (2) o surgimento de líderes conservadores em todo o mundo e suas políticas orientadas para o interno, como o governo de Donald Trump nos EUA; (3) o declínio da hegemonia americana na política global e a concomitante emergência da China como player robusto; e finalmente (4), o recrudescimento das fronteiras como limites importantes para "proteger" os territórios nacionais, a soberania, e até mesmo os padrões de vida, como o aumento do controle das fronteiras dentro do espaço Schengen (atualmente reintroduzido na França, Áustria, Alemanha, Dinamarca, Suécia e Noruega) para conter o fluxo livre de imigrantes indesejáveis e o forte lobby para a construção de um muro físico na fronteira Estados Unidos-México.

Como destacado por Scott (2006, p. 3) "[...] as questões de relações interestatais e da comunidade política são a respeito das fronteiras e de seu significado mais amplo". O aumento de securitização e controle de fronteiras (e, em alguns casos, de militarização) pelo estado tem sido um dos maiores desafios do regionalismo. Tal pode ser considerado uma resposta estatal a uma fase caótica e de crise abundante. Dupeyron (2017) recorda que os refugiados e os fluxos migratórios para a UE dividiram as políticas fronteiriças europeias com a restauração de pontos de controle e de rotinas e que o referendo que confirmou a saída do Reino Unido da UE reergueu as fronteiras britânicas para os cidadãos europeus. A prioridade dada às questões de segurança para as fronteiras dos EUA-Canadá criou uma "fronteira biométrica" e um campo hierárquico (em vez de cooperativo) de relações transfronteiriças. No tocante às fronteiras com o México, o fortalecimento da região econômica e cultural que formam não tem sido suficiente para impedir os EUA de investirem em mecanismos de controle adicionais, independentemente da construção de novos muros.

Evidências mostram que as ações dos atores que não se preocupam com as políticas regionais (ou agindo sem objetivos regionais) podem afetar como uma organização regional fechará ou abrirá suas fronteiras. Também pode influenciar como os estados reagem dentro de uma organização regional. Exemplos ilustrativos podem ser: a quebra do mercado de subprime do setor bancário dos EUA produziu uma longa crise financeira global que mais tarde 
foi traduzida em tumulto político em muitos países da UE, que agora apoiam movimentos anti-integração, que por sua vez pressionam políticos nacionais para deixar a UE e fechar suas fronteiras; o avanço do "apetite" chinês por bens primários na América Latina reduziu a capacidade do Mercosul de fortalecer sua indústria, afetando a forma como seus membros negociam tarifas comerciais internas (mais protecionistas); as regiões de fronteira (borderlands) tornaram-se muito atrativas para os atores de mercado devido à tributação especial em determinados países, mas também podem ser militarizadas devido ao aumento dos fluxos migratórios causados por conflitos internos em países terceiros.

A lista de exemplos poderia continuar indefinidamente. O que se demonstra é que a relação regionalismo-fronteira de hoje é de uma conectividade global multinível devido ao caráter multiescalar das dinâmicas fronteiriças e o resultado das políticas "intermésticas" vis-à-vis as conjunturas regionais e globais. Compreender o regionalismo como uma alternativa de nível médio não é suficiente para reconhecer os fatores que influenciam os fenômenos regionais e a relação entre as regiões e as fronteiras. Exatamente o oposto. Reconhecendo que o mundo está organizado em teias entrelaçadas de redes que atravessam todos os níveis geográficos (Dickon, 2015) nos permite identificar o regionalismo e a fronteira como componentes espaciais através dos quais os atores interagem em um sistema de redes múltiplas muito mais complexo, multicamadas e interconectado. Permite compreender como a concentração da atividade econômica e/ou do poder político em certas áreas influenciam a forma como o regionalismo e as fronteiras são utilizados pelos estados-nação e pelas organizações regionais. Une o regionalismo e as fronteiras como partes integrantes de um único macrossistema complexo.

\section{Considerações finais}

As noções de fronteira mudaram juntamente com as construções teóricas sobre o regionalismo. Se, na primeira fase, as organizações regionais estiveram no cerne das análises do regionalismo e as fronteiras foram compreendidas como acessórios estatais, a segunda fase mostrou uma compreensão mais complexa das funções fronteiriças vis-à-vis a rápida emergência de interconexões globais, transferindo sua atenção para tipos diversos de regiões. Por um lado, portanto, o antigo regionalismo replicava as noções de fronteira originadas nos estudos sobre relações estatais e interestatais; por outro lado, o novo regionalismo desenvolveu uma dupla noção de fronteira, como componente articular capaz de filtrar os intercâmbios de fluxos - abertos a alguns, mas fechado a outros. Uma diferença substancial é o reconhecimento das fronteiras e das regiões 
como respostas à globalização crescente no último, enquanto no primeiro o sistema internacional serviu como o molde para compreender tanto as regiões como as fronteiras.

A onda do regionalismo comparado é diferente de ambas as fases precedentes, na medida em que tem testemunhado o fortalecimento de processos aparentemente contraditórios: movimentos, organizações, competições e acordos (sub, inter, e intra)regionais - em macro ou microrrealidades, dos níveis local aos transnacional - ainda estão ganhando terreno nas relações globais; a reemergência das barreiras fronteiriças e dos nacionalismos - também dentro das organizações regionais, mas não exclusivamente; e o surgimento de muitas problemáticas globais e a subsequente demanda por uma governança também global. Ambos os processos atuam na formação de regiões (trans)fronteiriças, concomitantemente abertas e fechadas, locais e globais, nacionais e regionais. Por conseguinte, identificamos que a onda do regionalismo comparado tem enfatizado as chamadas interconexões multicamadas das fronteiras nas teias entrelaçadas das redes globais. Isto significa que, possivelmente, será muito mais intricado compreender e prever os papéis da fronteira (e das regiões, para todos os efeitos) aplicando um quadro analítico regional que não inclua uma perspectiva globalista dessas dinâmicas.

\section{Referências}

ACHARYA, Amitav. Comparative regionalism: a field whose time has come? The International Spectator, v. 47, p. 3-15, $2012<10.1080 / 03932729.2012 .655004>$.

AITKEN, Norman D.; LOWRY, William. R. A cross-sectional study of the effects of Lafta and CACM on Latin American Trade. JCMS: Journal of Common Market Studies, v. 11, n. 4, p. 326-336, $1972<10.1111 /$ j.1468-5965.1973.tb00918.x>.

ALBERT, Mathias; JACOBSON, David; LAPID, Yosef (orgs.) Identities, borders, orders: rethinking international relations theory. Minneapolis: University of Minessota Press, 2001.

ALTER, Karen J.; STEINBERG, David. The theory and reality of the European Coal and Steel Community. Evanston, IL: Northwestern University, 2007. p. 1-16.

ARCARAZO, Diego Acosta; GEDDES, Andrew. Transnational diffusion or different models? Regional approaches to migration governance in the European Union and Mercosur. European Journal of Migration and Law, v. 16, n. 1, p. 19-44, 2014.

$<10.1163 / 15718166-00002047>$.

ARNDT, H. W.; GARNAUT, Ross. Asean and the industrialization of East Asia. JCMS: Journal of Common Market Studies, v. 17, n. 3, p. 191-212, $1979<10.1111$ / j.1468-5965.1979.tb00618.x>.

BAERT, Francis; SCARAMAGLI, Tiziana; SÖDERBAUM, Fredrik. Intersecting interregionalism: regions, global governance and the EU. Dordrecht: Springer, 2014 $<10.1007 / 978-94-007-7566-4>$. 
BRESLIN, Shaun; HOOK, Glenn D. Microregionalism and world order. Houndmills: Palgrave Macmillan, $2002<10.1057 / 9781403940155>$.

BURKI, Shahid Javed. South Asia in the new world order: the role of regional cooperation. Oxon: Routledge, 2011.

DABÈNE, Olivier. The politics of regional integration in Latin America: theoretical and comparative explorations. New York: Palgrave Macmillan, 2009 $<10.1057 / 9780230100749>$.

DE LOMBAERDE, Philippe. How to 'connect' micro-regions with macro-regions? A note. Perspectives on Federalism, v. 2, n. 3, p. E29-E37, 2010.

DE LOMBAERDE, Philippe; SÖDERBAUM, Fredrik (orgs.). Introduction: reading the intellectual history of regionalism. In: Philippe De Lombaerde, and Fredrik Söderbaum (eds.). Regionalism. London: Sage, 2013. p. xvii-xlviii.

DÍAZ, Eugenia López-Jacoiste. The Latin American Integration Association. In: Marco Odello, and Francesco Seatzu (orgs.). Latin American and Caribbean International Institutional Law. New York: T.M.C. Asser Press, 2015. p. 23-42 <10.1007/978-946265-069-5>.

DICKEN, Peter. Global shift: mapping the changing contours of the world economy. New York: The Guildford Press, 2015.

DUPEYRON, Bruno. "Secondary foreign policy" through the prism of cross-border governance in the US-Canada Pacific Northwest border region. Regional \& Federal Studies, v. 27, n. 3, p. 321-340, $2017<10.1080 / 13597566.2017 .1343722>$.

ERIKSEN, Thomas Hylland. Globalization: the key concepts. New York: Berg Publishers, 2007.

FAWN, Rick. "Regions" and their study: wherefrom, what for and whereto? Review of International Studies, v. 35, p. 5-34, $2009<10.1017 /$ S0260210509008419>.

GAMBLE, Andrew.; PAYNE, Anthony. Regionalism and world order. London: Macmillan Press, 1996.

GÜLZAU, Fabian; MAU, Steffen; ZAUN, Natascha. Regional mobility spaces? Visa waiver policies and regional integration. International Migration, v. 54, n. 6, p. $164-$ 180, $2016<10.1111$ /imig. 12286>.

HAAS, Ernst. B.; SCHMITTER, Philippe. C. Economics and differential patterns of political integration: projections about unity in Latin America. International Organization, v. 18, n. 4, p. 705-737, $1964<10.1017 /$ S0020818300025297>.

HOOK, Glenn. D.; KEARNS, Ian. Subregionalism and world order. Houndmills: Macmillan Press, $1999<10.1007 / 978-1-349-14650-5>$.

HURRELL, Andrew. One world? Many worlds? The place of regions in the study of international society. International Affairs, v. 83, n. 1, 127-146, $2007<10.1111 / \mathrm{j} .1468$ 2346.2007.00606.x>.

KATZENSTEIN, Peter J. A world of regions: Asia and Europe in the American Imperium. Ithaca, NY: Cornell Universtiy Press, 2005. 
LAPID, Yosef. Introduction. Identities, borders, orders: nudging international relations theory in a new direction. In: Mathias Albert; David Jacobson; and Yosef Lapid (orgs.). Identities, borders, orders: rethinking international relations theory. Minneapolis and London: University of Minessota Press, 2001. p. 1-20.

LEIFER, Michael. The paradox of Asean. The Round Table, v. 68, n. 271, p. 261-268, $1978<10.1080 / 00358537808453337>$.

LELOUP, Fabienne; STOFFEL, Sophie. Intégration régionale et frontière dans le Mercosur: entre théorie, principes et réalités. Mondes en Développement, v. 3, p. 73-80, $2001<10.3917 /$ med.115.0073>.

MALAMUD, Andrés. Conceptos, teorías y debates sobre la integración regional. Norteamérica, v. 6, p. 219-249, 2011.

MANSFIELD, Edward L.; MILNER, Helen V. The political economy of regionalism. New York: Columbia University Press, 1997.

MATIUZZI DE SOUZA, Gustavo. Integração ou regionalismo? Estudando fronteiras na América Latina. In: William Soto Acosta (org.). Repensar las fronteras, la integración regional y el territorio. Heredia: Clacso, 2017. p. 125-132.

MATTHEIS, Frank; LITSEGÅRD, Andréas. Interregionalism Across the Atlantic Space. New York: Springer, $2017<10.1007 / 978-3-319-62908-7>$.

MORAVCSIK, Andrew; VACHUDOVA, Milada A. National interests, state power, and EU enlargement. East European Politics and Societies, v. 17, n. 1, p. 42-57, 2003 $<10.1177 / 0888325402239682>$.

NEWMAN, David. Borders and bordering: towards an interdisciplinary dialogue. European Journal of Social Theory, v. 9, p. 171-186, $2006<10.1177$ / $1368431006063331>$.

OHMAE, Kenichi. The end of the nation state - the rise of regional economies: how new engines of prosperity are reshaping global markets. London: Harper Collins, 1995.

PERKMANN, Markus; SUM, Ngai-Ling. Globalization, regionalization and crossborder regions. New York: Palgrave Macmillan, $2002<10.1057 / 9780230596092>$.

RIGGIROZZI, Pia; TUSSIE, Diana. The rise of post-hegemonic regionalism: the case of Latin America. London: Springer, 2012.

ROSAMOND, Ben. Theories of European integration. Houndmills: Macmillan Press, 2000.

SANTANDER, Sebastian. Invariances et ruptures dans le Mercosur. In: Sebastian Santander (org.). Relations internationales et régionalisme. Liège: Presses Universitaires de Liège, 2012. p. 12-32.

SCOTT, James Wesley. EU enlargement, region building and shifting borders of inclusion and exclusion. Aldershot: Ashgate, 2006.

SMOUTS, Marie-Claude; BADIE, Bertrand. Introduction. Cultures \& Conflits [en ligne], v. 21-22, p. s.p., 2006 [1996] <http://conflits.revues.org/236> (21 nov. 2017).

STRANGE, Gerard. Towards a new political economy of development: states and regions in the post-neoliberal world. London: Palgrave Macmillan, 2014 $<10.1057 / 9781137277374>$. 
SÖDERBAUM, Fredrik. Introduction: theories of new regionalism. In: Fredrik Söderbaum, and Timothy Shaw (orgs.). Theories of new regionalism. London: Palgrave Macmillan, 2003. p. 1-21.

SÖDERBAUM, Fredrik. Exploring the links between micro-regionalism and macroregionalism. In: Mary Farrell; Björn Hettne; and Luk Van Langenhove (orgs.). Global politics of regionalism: theory and practice. London: Pluto Press, 2005. p. 87-103.

SÖDERBAUM, Fredrik. Rethinking regionalism. London: Palgrave Macmillan, 2016.

SØRENSEN, Georg. Rethinking the new world order. London: Palgrave Macmillan, 2016.

VAN LANGENHOVE, Luk. Why we need to 'unpack' regions to compare them more effectively. The International Spectator, v. 47, p. 16-29, 2012 $<10.1080 / 03932729.2012 .655005>$.

VAUGHAN-WILLIAMS, Nick. Border politics: the limits of sovereign power. Edinburgh: Edinburgh University Press, 2009.

VIVARES, Ernesto (org.). Regionalism, development and the post-commodities boom in South America. London: Palgrave Macmillan, 2018.

WIENER, Antje; DIEZ, Thomas. European integration theory. 2. ed. Oxford: Oxford University Press, 2009.

WILLIAMS, John. Territorial borders, international ethics and geography: do good fences still make good neighbours? Geopolitics, v. 8, p. 25-46, 2003 $<10.1080 / 714001033>$.

YUE, C. S. The deepening and widening of Asean. Journal of the Asia Pacific Economy, v. 1, n. 1, p. 59-78, $1996<10.1080 / 13547869608724576>$.

Recebido em: 18 dez. 2017

Aprovado em: 26 mar. 2018

Autor correspondente:

Gustavo Matiuzzi de Souza

Rua Anita Garibaldi, 1786, apto. 414 - Boa Vista

90480-200 Porto Alegre, RS, Brasil

Gustavo MatiuZzi DE SoUZA < gustavo.matiuzzi@gmail.com>

Doutor em Ciências Sociais pela Pontifícia Universidade Católica do Rio Grande do Sul (Pucrs, Porto Alegre, RS, Brasil) e pela Université de Liège (ULG, Liège, Belgium), membro do Núcleo de Estudos sobre Relações e Organizações Internacionais na Pucrs em Porto Alegre, Brasil e docente no Center for International Relations Studies (Cefir) da ULG em Liège, Bélgica.

ORCID: http://orcid.org/0000-0003-3523-626X 